\title{
DANO AO PENSAMENTO E IDENTIDADE SUBJETIVA
}

\author{
H. Oppenheim-Gluckman*
}

\section{RESUMO}

A psicopatologia psicanalítica se preocupa com a questão da cognição. A partir da clínica de pacientes com lesão cerebral, este artigo busca pesquisar o lugar da cognição na economia psíquica de um sujeito e abrir vias para o trabalho psicoterapêutico com esses pacientes e seus familiares.

Palavras-chave: traumatismo craniano, cognição, identidade, inconsciente, subjetividade

\section{Abstract}

DAMAGE TO THINKING AND SUBJECTIVE IDENTITY

Psychoanalytic psychopathology takes cognition in consideration. From the clinic of patients with cerebral injury, this article tries to determine the place of cognition in the psychic economy of an individual and to open ways for the psychotherapeutic treatment of those patients and their relatives.

Keywords: cranial traumatism, cognition, identity, unconscious, subjectivity

Este texto se apóia numa pesquisa e numa prática clínica em pacientes com lesão cerebral. Traça "pistas de reflexão", pois o tema aqui abordado é difícil sob o ponto de vista clínico e epistemológico e, até agora, muito pouco explorado. Trata-se, a partir da clínica de pacientes com lesão cerebral, de localizar melhor o lugar da cognição na economia psíquica sob um ponto de vista metapsicológico. Esse tipo de abordagem pressupõe um confronto com a clínica neuropsicológica, sempre preservando o lugar de psicanalista e suas referências teóricas.

* Psiquiatra e psicanalista, Paris, França. 
A psicopatologia psicanalítica e o cognitivismo têm, com efeito, referências e modos de abordagem totalmente antinômicos. A psicanálise, como lembra Lacan (1973), é uma práxis centrada em torno da transferência e da causalidade psíquica inconsciente. As ciências cognitivas se situam ao lado de uma psicologia experimental e da causalidade científica. No entanto, a partir da clínica de pacientes portadores de distúrbios cognitivos (pacientes psicóticos, autistas, dementes, com lesão cerebral), a psicopatologia psicanalítica se preocupa com a questão da cognição.

Em relação ao modo de abordar a questão da cognição, no seio do movimento psicanalítico, as posições não são de forma alguma unificadas. Assim, na França, para Widlocher (1993), a psicopatologia do inconsciente psicanalítico repousa sobre mecanismos elementares que somente podem ser explicados pela psicopatologia cognitiva. A psicanálise abriria um campo muito grande e específico ao estudo desses mecanismos. Nos Estados Unidos, um psicanalista como Solms (2000) busca criar um campo específico, a "neuropsicanálise" ou a "neuropsicologia das profundezas", que permitirá correlacionar elementos extraídos da metapsicologia freudiana (por exemplo, uma instância como o Eu) com as localizaçōes cerebrais (por exemplo, o lobo frontal).

Uma tentativa semelhante existe em L. Lewis (1992). A partir dos conhecimentos atuais sobre as diferentes funções dos dois hemisférios cerebrais, a autora formula a hipótese de que as técnicas psicoterápicas são eficazes porque permitem ao conteúdo mental do hemisfério direito (sede dos processos primários) se integrar ao hemisfério cerebral esquerdo (sede dos processos verbais e conscientes). Retomando a fórmula de Freud, "Lá onde o Isso estava, o Eu deve advir", ela a transforma em "ajuda o hemisfério esquerdo a melhor compreender o hemisfério direito" (Lewis, 1992: 21).

No que me concerne, tento abordar o problema da cognição a partir da clínica de pacientes que, em virtude de lesões cerebrais conseqüentes a traumatismos cranianos, tumores, acidentes vasculares, etc, apresentam danos cognitivos tais como distúrbios de linguagem, da memória, do gesto, do reconhecimento de rostos, de orientação no tempo e no espaço. Ao me situar no campo da causalidade psíquica inconsciente, e por fora de toda lógica de causalidade do tipo etiológica, portanto fora do debate organogênese ou psicogênese, tento, dentro do quadro de uma relação transferencial com os pacientes, compreender com qual tipo de experiência subjetiva estes são confrontados quando sofrem uma perturbação das categorias de pensamento por razôes orgânicas. Tento compreender também o que se passa do ponto de vista de sua economia psíquica quando obrigados a enfrentar esses danos. Essa abordagem é, portanto, centrada no que constitui um "fato psí- 
quico" para o sujeito e diferencia o fato de apresentar uma lesão cerebral como estado neurológico de apresentar uma lesão cerebral como "fato psíquico".

Minhas questôes são as seguintes: como a lesão cerebral, a doença, as perturbaçôes cognitivas se integram na vida fantasmática do sujeito e de seu círculo, na sua história familiar pessoal consciente e inconsciente? Quais são as conseqüências da doença e das perturbaçôes cognitivas sobre a economia psíquica do sujeito? A partir destas questôes, busco compreender os modos de organização de processos psíquicos intra e intersubjetivos e, num segundo tempo, confrontá-los com os dados médicos e neuropsicológicos (Oppenheim-Gluckman, 2000). Dessa forma, situo-me na perspectiva de uma psicopatologia que se deseja livre da preocupação com a etiologia e da causalidade científica, bem como, assim espero, no quadro de uma psicopatologia mais próxima da causalidade psíquica inconsciente. Esse tipo de abordagem, aplicada aqui à clínica dos pacientes com lesão cerebral, me parece ser uma abordagem possível para a psicanálise em relação a outras patologias, como a psicose, o autismo, as demências, nas quais as perturbaçôes cognitivas foram identificadas. Ela poderá lhe permitir delimitar seu campo e seu lugar, quaisquer que sejam, de resto, os avanços de conhecimento biológico e neuropsicológico em relação a qualquer enfermidade. Possui bases clínicas na medida em que influi nas modalidades de escuta e de abordagem desses pacientes e de seus familiares.

Vou abordar a questão do lugar da cognição para a economia psíquica do sujeito a partir de três exemplos: cognição e sentimento de si, cognição e emergência do inconsciente e relação com a temporalidade.

\section{CogniçÃo E SENTIMENTO DE SI}

A clínica de pacientes portadores de lesão cerebral mostra que os distúrbios cognitivos atingem o sujeito em seu sentimento de identidade e de existência na medida em que tal sentimento é sustentado pela memória, pela imagem do corpo, pelo esquema corporal, pela relação com o espaço e a temporalidade, mas também pela continuidade da relação com o outro e pela manutenção dos processos de inter-reconhecimento entre si mesmo e o outro. Nos pacientes com lesão cerebral, o prejuízo do sentimento de identidade e de existência se traduz pelas "angústias de catástrofe", descritas por K. Goldstein (1951: 118) nos seguintes termos: "elas nascem da experiência íntima do enfermo que percebe muito melhor um abalo do mundo que o rodeia do que o de sua própria pessoa”. Com as referências mais psicanalíticas, as angústias que invadem esses pacientes podem ser relacionadas às "angústias primitivas" que Winnicott descreve em seu artigo "Medo do colapso" 
(1975). Essas angústias primitivas, diz o autor, traduzem um fracasso da edificação do "self unitário", e acrescenta: "é a organização do eu que é ameaçada" (Winnicott, 1975a: 38).

A noção de si apareceu nos escritos psicanalíticos tardiamente, refiro-me aos trabalhos de Kohut e Winnicott. Noções como a de narcisismo primário ou secundário ou como a do Eu, descritas por Freud, não permitem apreender toda a sua complexidade.

Tendo como suporte os trabalhos de Dolto (1984), poderíamos afirmar que o dano cognitivo induz a um abalo do que a autora denomina "narcisismo primordial", isto é, "a sensação de mesmidade do ser" (Dolto, 1984: 76), ou melhor, se adotarmos as referências mais "winnicotianas", poderíamos dizer que as enfermidades cognitivas colocam o self em perigo. Para esse autor, o sentimento de existência se apóia sobre o desenvolvimento de um "eu integrado" e do self. Enquanto a criança se encontra em um estado de imaturidade motora e cognitiva, esse "eu integrado" e esse self se constroem e se tornam possíveis dentro do processo de desenvolvimento da criança graças à relação de sustentação fornecida ao bebê pela "mãe suficientemente boa", capaz de proteger a criança das angústias terríveis associadas a essa imaturidade (se fragmentar, não parar de cair, não ter orientação, não ter relação com o próprio corpo). A mãe tem, portanto, uma função de suporte e de suplência, entre outras, em relação à imaturidade cognitiva e corporal da criança. Esse suporte vai se tornar inútil quando diversos processos psíquicos de maturação descritos pela psicanálise puderem se produzir, mas também, o que muitas vezes nos esquecemos de enfatizar, quando uma cognição e uma motricidade desenvolvidas puderem se instalar.

A clínica dos pacientes com lesão cerebral mostra que a cognição tem uma função de suporte interno para o sujeito e lhe permite integrar em seu espaço psíquico as representaçóes de si e do mundo próprias a cada um. A presença de distúrbios cognitivos coloca o sujeito numa situação de dependência física, social e quotidiana em face de seu ambiente, mas também em um estado de dependência psíquica, impossibilitado que se encontra de poder se apoiar sobre as próprias percepções e representações de si e da realidade que o rodeia. Assim, certos pacientes com lesão cerebral, em conseqüência de distúrbios mnêmicos, de perturbações no reconhecimento de rostos, ou de reconhecimento de objetos, por exemplo, não podem mais se apoiar sobre o próprio sistema de representações para falar de si mesmos e do mundo que os rodeia. Utilizam as palavras de seu próximo como "próteses de representação". Refiro-me a "prótese de representaçôes" quando o sujeito se apóia sobre elementos externos a si mesmo para tentar representar o acidente para si mesmo, suas conseqüências, sua biografia, o mundo que o ro- 
deia, em falta de "representação interna". Se certos pacientes podem identificar as "próteses de representação" que utilizam como lhes sendo externas (e portanto perceber que tomam como próprio o discurso de um outro), outros, ao contrário, não podem mais falar em seu próprio nome e dizer "eu". Quando os pacientes utilizam as "próteses de representação" dessa forma, podem ter um discurso sobre determinado acontecimento, mas o caminho que conduz do discurso à experiência vivida e sentida fica barrado. O significado emocional e pessoal da percepção desse acontecimento passa a não existir mais. Na clínica quotidiana, é importante diferenciar esse mecanismo de negação, sobretudo em certas elaborações teóricoclínicas como as que dizem respeito ao desconhecimento ou anosognosia dos distúrbios cognitivos e comportamentais (Oppenheim-Gluckman, 2000).

O que acontece quando o sujeito se encontra numa situação como essa? Há uma experiência de clivagem, com a coexistência de dois sistemas separados: o discurso e a representação interna e experimentada que não se relaciona ao discurso em questão e que pode até mesmo ser contraditória em relação a esse discurso. Assim, por ocasião de seu acidente, Norbert estava ao volante. Sua amiga está morta. Ele não consegue acreditar no acidente que lhe foi relatado, mesmo sabendo que sua amiga está morta. Ele vive "como se", para não "passar por maluco". Aqui, a dificuldade de Norbert para poder integrar o acidente em seu espaço psíquico encontra-se na convergência da amnésia pós-traumática e de elementos de culpabilidade. Entretanto, a clivagem entre seu discurso e a ausência de lembrança da experiência do acidente se deve às conseqüências das lesões cerebrais que induziram uma amnésia. Esse tipo de experiência, induzida pelos distúrbios cognitivos na clínica a que me refiro aqui, favoreceria um "falso self". No artigo "O conceito de falso self", Winnicott diz que "cada indivíduo tem um self polido ou socializado e um self pessoal, privado, que só é accessível na intimidade (Winnicott, 1988: 76). Na vida quotidiana, e no sujeito normal, habitualmente é possível existir um compromisso entre o "verdadeiro" e o "falso self . O self polido e socializado, quando resultado de uma crença pessoal, e não de uma adaptação superficial, não impede o sujeito de se sentir existir, apoiando-se sobre o seu verdadeiro self. Em certas doenças pode haver uma clivagem bastante profunda entre esse "verdadeiro" e esse "falso self, cujo ponto mais extremo, segundo Winnicott, vem a ser a esquizofrenia. Em alguns pacientes com lesão cerebral, em virtude dos danos cognitivos e de sua conseqüência para os processos psíquicos, reencontra-se essa clivagem entre o "verdadeiro" e o "falso self" e um "falso self" em primeiro plano. Certas experiências e representaçôes de si e do mundo são valorizadas ou enunciadas em função do discurso, das necessidades e dos desejos de um outro, porque o sujeito com lesão cerebral tem necessidade de se apoiar nas representa- 
çôes dos outros e de com elas encontrar um discurso comum, mesmo que seja artificial. Mas essas representações de si e do mundo se distanciam de fato das experiências e das representaçôes que o sujeito pode realmente atribuir a si mesmo e experimentar, as quais seriam o fundamento de um "verdadeiro self".

Todos os elementos mostram que o outro não é apenas um "cérebro assistente" para os pacientes com lesão cerebral (para retomar a expressão utilizada por um de meus pacientes), isto é, uma ajuda ou uma suplência para a realização de tarefas cognitivas que o paciente não consegue mais realizar. $\mathrm{O}$ outro tem também uma função de suporte, como uma "mãe suficientemente boa" (Winnicott, 1988). Ele supre as deficiências dos processos de sustentação interna que se devem aos danos cognitivos. Há também uma função de suporte de "próteses de representação". Essa função é inevitável em virtude da situação criada pelos danos cognitivos, mas é intrinsecamente geradora de mecanismos de alienação e de criação de um "falso self.

O prejuízo da sensação de identidade e de existência, vivido pelo sujeito com lesão cerebral, também se deve à dificuldade que este sente quando vive a experiência da intersubjetividade. Essa experiência é um dos fundamentos da sensação de si, como demonstrou Winnicott, e mais recentemente Daniel Stern (1989), que se apóia ao mesmo tempo na psicanálise e na psicologia do desenvolvimento. Viver a experiência da intersubjetividade supóe a existência de um quadro comum de significaçōes e de meios de comunicação, um jogo de linguagem (verbal ou não) partilhado e partilhável. É necessária a existência de um quadro de significação comum, possível entre o sujeito e o outro, em torno da linguagem verbal, mas também em torno do não-verbal (gestos, posturas, expressões faciais, etc...). Ora, em conseqüência dos danos cognitivos, a possibilidade desse quadro comum de experiências subjetivas, partilhado, encontra-se prejudicada. Com efeito, em virtude desses danos, o universo subjetivo dos pacientes e sua compreensão do mundo tornam-se distintos.

Vou apresentar dois exemplos disso. No caso de amnésia, a perda das lembranças e sua reconstrução com a ajuda de suportes externos (fotos, relatos de parentes) não permitem ao paciente atribuí-las a si. Ou seja, para retomar as palavras de um de meus pacientes, "trata-se de reportagens irrelevantes nas quais se está sem se estar". Daí a ausência de uma experiência ligada à lembrança, daí a dificuldade de contar a história da própria vida com todas as possibilidades de modificar a maneira pela qual nós próprios nos enxergamos e enxergamos os outros e os acontecimentos, daí também a dificuldade de partilhar com o outro essas lembranças. Isso altera as possibilidades de empatia e de intersubjetividade. Da mesma forma, quando sucedem certos danos no hemisfério direito e no lobo 
frontal, ocorre perda do sentido da metáfora. Nessas condições, a palavra pronunciada pelo paciente ou por um outro é percebida sem polissemia, portadora de um único sentido. Nesse caso, a experiência de um laço interpessoal e intersubjetivo através de uma significação partilhada se torna muito difícil. Alguns pacientes com lesão cerebral apresentam dificuldade em perceber a intensidade e o sentido emocional daquilo que os rodeia, especialmente dos rostos. Isso acarreta também grande dificuldade para a existência de um quadro de significação em torno do "não-verbal". Nessas condições, um jogo de linguagem comum e transmissível se torna igualmente muito difícil.

Dore (citado por Stern) formulou a hipótese de que a linguagem age no começo da vida como um "fenômeno transicional" tal como descrito por Winnicott. O que significa que ela ocupa uma posição intermediária entre o eu e o não-eu. Eu aventaria a hipótese de que certos processos cognitivos como a linguagem, a memória, e outros ainda, como a possibilidade de reconhecer as fisionomias familiares, na medida em que são necessários à diversidade das imagens e das representações de si, dos outros, dos acontecimentos, na medida em que são necessários a um jogo de linguagem partilhado e partilhável e a uma "coconstrução" da intersubjetividade, constituem um suporte necessário (mas não suficiente) àquilo que Winnicott denominou "área da ilusão" (Winnicott, 1975a: 39). Esse espaço, em que fantasma e realidade se superpõem, que perdura no adulto, como lembra Winnicott, é "uma raiz natural da constituição dos grupos humanos" e se encontra na base da criatividade (Winnicott, 1975a: 18). O dano desse suporte vai intervir também no dano ao sentimento de identidade e de existência.

\section{COGNIÇÃO E EMERGÊNCIA DO INCONSCIENTE}

Por ocasião de casos de despertar de um coma neurocirúrgico, os quais podem ser considerados como danos cognitivos maiores, descrevi o que chamei metaforicamente de "inconsciente desligado" (Oppenheim-Gluckman, 1996: 26). Trata-se do momento em que há uma expressão direta de representações e afetos recalcados sem as formações de compromisso sintomaticamente habituais, quando há uma emergência do inconsciente.

Da mesma forma, quando se produzem danos mnésicos com fabulações, que a psicologia cognitiva explica através de diversos mecanismos, descrevi a forma pela qual o conteúdo das fabulações (e não seu mecanismo explicado pela psicologia cognitiva) testemunha a expressão dos processos primários, a emergência do espaço do sonho, esse último dominando os processos de pensamento (Oppenheim-Gluckman, 2000). 
O fato de que o conteúdo das fabulações (e não seus mecanismos explicados pela psicologia cognitiva) testemunhe a expressão dos processos primários, da emergência do espaço do sonho, não é contraditório com outros trabalhos.

A partir de 1968, Weinstein e Liverly interpretaram as fabulações como um distúrbio do simbolismo comparável ao que aparece no sonho. Elas representariam metaforicamente os problemas inconscientes do paciente e seus sentimentos sobre si próprio (Weinstein e Liverly, 1968). Recentemente, a partir de entrevistas clínicas, Solms (2000) demonstrou que a vida dos pacientes com fabulações era dominada pelos processos inconscientes descritos por Freud, com a substituição da ligação com a realidade externa pela realidade psíquica, pela emergência dos processos primários. $\mathrm{O}$ autor faz uma analogia entre as fabulaçôes e os processos do sonho. Os estudos realizados sobre o sonho, a partir da abordagem da psicologia cognitiva de Hobson (1996), não se mostram incompatíveis com as hipóteses desenvolvidas sobre as fabulações por Solms ou por mim mesma. Segundo Hobson, os mecanismos cognitivos que intervêm no sonho são os seguintes: desorientação, deficiência de atenção, prejuízo da memória imediata e recente, tendo como corolário as fabulaçôes (Hobson, 1996). Mark J. Blechner, que por sua vez também trabalha sobre o sonho, ressalta que neste todos nós somos "fabuladores" (Blechner, 2000). As fabulaçôes no sonho serão religadas ao que o autor denomina "cognições disjuntivas" (cognição disjunta na qual dois aspectos da percepção e da representação encontram-se defasados) e às distorções da temporalidade (que existem no sonho, mas também em certos pacientes com lesão cerebral).

Os elementos que acabei de descrever aqui suscitam numerosas questôes: em certos casos, o prejuízo da cognição favoreceria a atenuação dos processos de censura e de recalque? Os processos cognitivos, que deveriam ser definidos de modo mais preciso, seriam necessários para o funcionamento dos processos secundários? Por meio de que mecanismos?

É difícil responder a essas questões apenas a partir dos trabalhos atuais. Há todo um campo de trabalho a ser desenvolvido, inicialmente entre os psicanalistas, depois, num segundo tempo, em confronto com os neuropsicólogos. Um trabalho interdisciplinar permitiria melhor compreender a relação entre cognição e emergência do inconsciente nos pacientes com lesão cerebral e, a partir desse modelo, quando não existe qualquer dano cognitivo.

Há poucos elementos na teoria freudiana sobre a cognição, e as principais elaborações realizadas pelos psicanalistas concernem, sobretudo, aos sujeitos que não utilizam os meios cognitivos de que dispõem por razôes psicopatológicas. Entretanto, alguns psicanalistas elaboraram algumas hipóteses. 
Stern, em $O$ mundo interpessoal do lactente (1989), formula a hipótese de que as deformações fantasmáticas e a atitude dos mecanismos de defesa a partir de um ponto de vista psicodinâmico necessitam de processos cognitivos elaborados e são, portanto, uma atitude tardia do bebê.

Solms (2000) levanta a hipótese de que algumas estruturas da região frontal ventromediana do cérebro seriam necessárias para o funcionamento secundário que caracteriza o sistema pré-consciente-consciente.

No que me concerne, prefiro a hipótese de que na presença de certos distúrbios cognitivos haverá uma perturbação do "Princípio de realidade" descrito por Freud e, portanto, emergência do espaço do sonho e dos processos primários (Freud, 1911 [1984]).

No texto "Neurose e psicose", Freud descreve a neurose como "resultado de um conflito entre o Eu e o isso", e a psicose como "resultado análogo de um conflito entre o Eu e o mundo exterior". Na psicose, diz ele, a "loucura é uma peça que se fixa lá onde se produziu uma falha na relação do Eu com o mundo exterior". Freud sublinha o parentesco entre a psicose e o sonho. Também na neurose existe uma falha entre o Eu e o mundo exterior, mas ela é obturada pelo "princípio de realidade" (Freud, 1924 [1978]). Em caso de dano cognitivo, a fratura entre o Eu e o mundo exterior se deve, de um lado, à perda das capacidades cognitivas que permitem o contato com a realidade e sua integração no espaço psíquico e, de outro lado, a um conflito entre o Eu e a percepção de uma realidade exterior intolerável, freqüentemente estranha, a qual, subitamente, em virtude dos distúrbios cognitivos, deixa de ser familiar. Nessas condições, as fabulações seriam, talvez, "a peça que se fixa onde uma falha se produz na relação entre o eu e o mundo exterior" (Freud, 1933 [1975]: 80).

A multiplicidade de hipóteses, tanto as minhas quanto as dos colegas, quando diante de certos danos cognitivos, constitui um modo particular de dano à identidade e introduz o paciente em múltiplos espaços: o espaço do Inconsciente e o do sonho dos quais acabo de falar. Quando os pacientes se encontram no espaço do Inconsciente, a relação com o tempo é a do Inconsciente, que, segundo Freud, não conhece o tempo social (Freud, 1915 [1978]). Os pacientes são presos no espaço de sua história inconsciente, com retorno, vivido como atual, de períodos anteriores significativos, esquecidos mas não ultrapassados, e atualização de antigos conflitos infantis recalcados que aparecem aqui como se o tempo jamais tivesse escoado.

O espaço do íntimo. Aqui se pode falar de uma violenta efração, que coloca o sujeito em relação direta com seu Inconsciente e provoca uma irrupção do íntimo no cotidiano além dos limites admissíveis habitualmente. Essa efração pode 
gerar um traumatismo psíquico, caso o sujeito e os outros não sejam capazes de se reconhecer no discurso enunciado pelo paciente. Nessas condições, o sujeito com uma lesão cerebral se vê, ao mesmo tempo, próximo e distante de si mesmo. Distante, porque aparece desprovido de certo número de seus próprios atributos identificatórios, de seus mecanismos de defesa; próximo porque está em contato mais direto com seu Inconsciente. Porém a intuição ou a sensação de uma proximidade em relação a si mesmo só pode existir sob a condição de que o paciente possa se reconhecer como sujeito de seu discurso e ser reconhecido como tal por um outro, o que é muito difícil fora do quadro da psicoterapia.

O espaço de desvelamento do mal-entendido entre si e o outro, constitutivo do humano, nesse caso se desvela em toda sua "crueza", por falta de uma referência mínima à mesma realidade contextual e temporal.

Além disso, a questão das fabulaçôes introduz o terceiro ponto deste texto, a relação com o tempo vivido.

\section{A RELAÇÃO COM O TEMPO VIVIDO}

A partir de um ponto de vista neuropsicológico e comportamental, nos pacientes com lesão cerebral freqüentemente são descritas uma grande lentidão e uma desorientação temporal. As perturbações mnésicas as favorecem. As perturbações da memória imediata ou da memória episódica introduzem, efetivamente, uma alteração na relação com o tempo vivido. A memória episódica é um dos componentes da memória autobiográfica no modelo de Tulving: trata-se da memória de acontecimentos pessoais específicos vividos e se opõe à memória semântica, que reagrupa os conhecimentos mais gerais sobre seu passado (por exemplo, seu lugar de trabalho, o nome de seus colegas, etc...). Os trabalhos de psicologia cognitiva sobre a memória episódica demonstraram que certos pacientes com lesões frontais eram afetados na memória para a ordem temporal (Piolino, P., Desgranges, B., Eustache, F., 2000).

Nos pacientes com lesão cerebral, a complexidade da relação com a temporalidade ilustra a diferença e a complementaridade das abordagens neuropsicológicas e psicopatológicas.

Assim, a lentidão não é somente um elemento quantitativo (os pacientes com lesão cerebral são mais lentos que os normais). Reflete também outra forma de ser e de pensar. No caso de perturbações motoras ou neurológicas, é a sensação de um corpo ou de partes do corpo que não mais se domina, ou de um corpo que vacila, que treme. No caso de perturbações cognitivas, existe o sentimento de um permanente descompasso entre si mesmo e os outros, quando essa lentidão refle- 
te, entre outras coisas, a dificuldade de integração e de tratamento cognitivo das mensagens advindas da realidade exterior e a dificuldade para elaborar suas próprias respostas em face dessa realidade. Essa experiência faz revolverem-se os sinais familiares e habituais do paciente e de seu ambiente. É de tal forma perturbadora que dificilmente será transmissível. Daí o sentimento do paciente de estar num "outro mundo", "de não falar mais a mesma língua que os outros".

De forma geral, a neuropsicologia readaptativa diagnostica, com a ajuda de testes, a desorientação temporal e as perturbações mnêmicas. Ela aperfeiçoa a relação do paciente com a realidade cotidiana através de um trabalho reeducativo e readaptativo que o ajuda, entre outras coisas, a se reapropriar do tempo social (o dia, a hora, o respeito pelos encontros), seja por aprendizagem, seja pelo emprego de meios de suplência, como, por exemplo, a manutenção de uma agenda. A psicopatologia, por sua vez, está centrada na alteração da relação com o tempo vivido, o que se dá em função da lesão cerebral. Essa alteração repercute sobre a identidade subjetiva. Assim, apesar da utilização do tempo social, para muitos pacientes a temporalidade é uma experiência que eles não experimentam mais. Sabem a data, sua idade, mas é um saber exterior a eles. Não se encontra mais integrado ao seu espaço psíquico. Em função de distúrbios da memória imediata, alguns pacientes redescobrem o mundo que os rodeia a cada instante.

É possível diferenciar a temporalidade social e a temporalidade experimentada. Quando a temporalidade não é sentida, modifica a compreensão do mundo exterior, dos fantasmas e da vida psíquica, tal como inscritos em uma temporalidade. Essas modificações têm conseqüências sintomáticas; por exemplo: o surgimento de condutas de tipo obsessivo para criar referências a fim de poder sobreviver psiquicamente, ou o surgimento de uma indiferença emocional que não deve ser confundida com afetos depressivos.

Alguns pacientes permanecem fixados no tempo da infância em virtude de, entre outros, distúrbios mnêmicos.

É o caso da Sra. A., que "perdeu" dez anos de sua vida depois de um acidente de carro. Vinda da Argentina, ela não tem nenhuma lembrança de sua chegada à França, de seu casamento, do nascimento de seu filho. O espaço da França, seu estatuto de esposa e de mãe são artificiais para ela. Quando fala de modo repetitivo de sua vida atual, diz que se sente "como hóspede" na casa de um homem que é seu marido. $\mathrm{O}$ único espaço que tem algum sentido para ela e no qual se reencontra é o de seu país natal, que representa o tempo da infância, pelo qual pode experimentar algum sentimento de familiaridade e vivenciar possíveis lembranças. Bem que tentou se comportar como uma mãe e uma esposa, porque lhe foi dito que assim deveria fazer e porque possui uma percepção confusa dessa vivência 
e dessa experiência, mas efetivamente se encontra no tempo da infância (as lembranças e os afetos daquela época), por falta de lembranças sentidas de sua vida posterior. Isso é percebido por seu marido, que repete "que, agora, ele tem duas crianças na casa", e também pelo seu filho, que lhe diz: "se você fizer uma bobagem, eu vou contar para o papai, ele vai te dar uma surra". Ela mesma fala de dificuldades no casal, dizendo: "meu marido me repreende". Não consegue falar de sua chegada à França e de seu casamento e, posteriormente, de sua maternidade sem se apoiar no discurso de seu marido e de sua família, mas esses acontecimentos são para ela um saber, não uma vivência. Em virtude de seu distúrbio de memória episódica, não há possibilidade de partilhar, de modo autêntico, lembranças comuns com seu marido.

Boris, 20 anos, também permanece fixado no tempo de infância por falta de recursos cognitivos para sair de lá e porque a extrema dependência na qual se encontra, em função das conseqüências cognitivas e motoras de seu traumatismo craniano, impede que se confronte com as experiências necessárias que os processos psíquicos de maturação (adolescência, entrada na idade adulta) permitem. Criança brilhante na sala de aula, tinha dez anos quando sofreu grave traumatismo craniano, seguido de muitos anos de hospitalização. Apresenta sérios distúrbios mnêmicos e uma síndrome frontal maciça. Agarra-se repetidamente a duas ou três "ilhotas" de lembranças que o fazem parecer muito infantil aos olhos de todos. Chamavam-no de "francboris" porque ele era muito bom em francês, uma blague com o nome de família de um de seus amigos, na ocasião em que vivia no estrangeiro, período muito feliz para ele; fragmentos de Tintin. Essas "ilhotas de lembranças" fazem com que Boris pareça "fixado" no tempo de infância. Mas são, além disso, tentativas de manutenção de sua identidade subjetiva, de "palavras de ligação" e de referências necessárias que lhe permitam religar-se à sua história e aos modos de ser que lhe são familiares. No caso desse paciente, uma posição educativa e readaptativa centrada numa evolução de seus comportamentos infantis não adaptados socialmente teve por conseqüência a perda de suas "bóias identitárias" e, talvez, das suas únicas possibilidades de troca com os outros.

Portanto, os danos cognitivos permitem colocar em evidência de forma "quase" experimental os diferentes níveis e espaços de temporalidade existentes no indivíduo.

\section{Conclusão}

A articulação entre psicanálise e ciências cognitivas, levando em conta seus modelos diferentes, é muito difícil. Parece ilusório buscar criar conceitos que permi- 
tam uma unificação desses dois campos. Ao contrário, confrontações, a partir da clínica dos pacientes que sofrem danos cognitivos, em torno da abordagem específica de cada um podem ser estimulantes. Hoje em dia, essa clínica deveria ser um dos paradigmas da psicanálise, no mesmo nível daqueles em torno dos quais ela se construiu até o momento atual.

\section{REFERÊNCIAS BIBLIOGRÁFICAS}

Blechner, M. J. (2000). Confabulation in dreaming, psychosis and brain injury. Em Neuropsychoanalysis, 2, 139-144.

Dolto, F. (1984). L'image inconsciente du corps. Paris: Seuil.

Freud, S. (1911). Formulations sur les deux principes du cours des évènements psychiques.

Em Résultats, idées, problémes I (pp. 135-44). Paris: PUF, 1984.

Freud, S. (1915). L'inconscient. Em Métapsychologie (pp. 65-124). Paris: Gallimard, 1978.

Freud, S. (1924). Névrose et psychose. Em Névrose, psychose et pèrversion (pp. 283-86). Paris: PUF, 1978.

Freud, S. (1933). Lecture XXXI. Em New Introductory Lectures, Standard Edition, vol. XXII. London: The Hogarth Press, 1975.

Goldstein, K. (1951). La structure de l'organisme. Paris: Gallimard.

Hobson, J. A. (1996). Dreaming as delirium: a mental state analysis of our night madness. Revue Internationale de Psychopathologie, 23, 523-540.

Kaplan-Solms, K.; Solms, M. (2000). Clinical studies in neuro-psychoanalysis. New York: Karnac.

Lacan, J. (1973). Les quatre concepts fondamentaux de la psychanalyse. Paris: Seuil.

Lewis, L. (1992). Two neuropsychological models and their psychotherapeutic implications. Bulletin of the Menninger Clinic, 56, 20-32.

Oppenheim-Gluckman, H. (1996). Mémoire de l'absence, clinique psychanalytique des réveils de coma. Paris: Masson.

. (2003). La représentation du vivant. Evolution Psychiatrique, 68, 4, 669-674.

Lyon, France.

—. (2006). La pensée naufragée, clinique psychopathologique des patients cérébrolésés. Paris: Anthropos.

Piolino, P., Desgranges, B., Eustache, F. (2000). La mémoire autobiographique: théorie et pratique. Marseille: Solal.

Solms, M. (2000). A psychoanalytic perspective on confabulation. Neuropsychoanalysis, 2 (2), 133-44.

Stern, D. (1989). Le monde interpersonnel du nourrisson. Paris: PUF. 
Weinstein, E. A.; Lyverly, O. G. (1968). Confabulations following brain injury: its analogue and sequelae. Archives General of Psychiatry, 18, 348-454.

Widlocher, D. (1993). Intentionnalité et psychopathologie. Revue Internationale de Psychopathologie, 10, 193-224.

Winnicott, D. W. (1974). Intégration du moi au cours du développement de l'enfant. Em Processus de maturation chez l'enfant (pp. 9-18). Paris: Payot.

- (1974). Distorsions du moi en fonction du vrai et du faux self. Em Processus de maturation chez l'enfant (pp. 115-132). Paris: Payot.

. (1974). Le passage de la dépendance à l'indépendance dans le développement de l'individu. Em Processus de maturation chez l'enfant (pp. 43-54). Paris: Payot.

. (1975a). Objets transitionnels et phénomènes transitionnels. Em Jeu et Rréalité (pp. 7-39). Paris: Gallimard.

. (1975b). La crainte de l'effondrement. Nouvelle Revue de Psychanalyse, 11, 3544. Paris.

(1988). Le concept de faux soi, Conversations ordinaires. Paris: Gallimard.

Recebido em 10 de janeiro de 2006 Aceito para publicação em 23 de março de 2006 